\title{
Social class and Sociology - the state of the debate between 1967 and 1979
}

\author{
Louise Ryan and Claire Maxwell
}

\begin{abstract}
As part of the 50th anniversary celebration of the journal Sociology, four e-special issues have been produced to explore specific themes across the journal's history. In this e-special, we examine how social class has been discussed during the early years of the journal, 1967-1979. Based on our selection of ten past articles, and two more recent articles, we examine two broad themes. First, we consider how social class has been conceptualised, paying particular attention to the notion of embourgeoisement. Second, we turn to methodological considerations and discuss how approaches to researching class have evolved over time. This e-special provides not only an opportunity to celebrate the Sociology back catalogue but also to re-appraise some of the classic contributions from the first decade of the journal's history.
\end{abstract}

\section{Key words}

social class, embourgeoisement, methodology, ethics, Sociology

\section{Introduction}

To celebrate the $50^{\text {th }}$ anniversary of the journal, it was decided by the editorial board and our publishers Sage to produce four e-special issues commemorating particular themes from across the decades. There was much discussion among board members about whether the four e-special issues should be divided by theme, by time period or some other way. In the end, it was decided to focus on specific themes within particular decades. This is not to suggest that a topic was only studied in one decade. We recognised of course that examining class in the 1960s-70s and not in the 1990s, for example, is somewhat artificial. We could equally have focused on gender in the 1990 s and class in the 1980s. Rather, our intention here is simply to understand how a particular theme was conceptualised, researched and analysed during one specific period of the journal's history. Breaking it down by decades is largely a way of making this huge task manageable within a rather tight time frame and to ensure publication within the anniversary year of the journal [1].

Reviewing the back catalogue of Sociology is like entering an Aladdin's Cave of rich sociological heritage. It is truly a treasure trove filled with famous names; a veritable Who's Who of academic writing and research. Trawling through the years 1967-1979, we were struck by how many familiar names were writing in the journal right from the start of its publication: Lockwood, Goldthorpe, Crompton, Bernstein, etc. Perhaps more surprising than all the 'star' sociologists, were the many unfamiliar names; those who had been active at the cutting edge of sociological endeavour in the late 1960s and early 1970s, but who are now largely forgotten. In making our selection, we were keen to include not only the well-known, 'star' sociologists but also those who are now less well known.

Our selection criteria, therefore, were not just fame and longevity, but rather the innovation of their work. Clearly no collection on class in Sociology from 1967-1979 would be complete without names like Goldthorpe or Lockwood and, no doubt, we would be criticised if we did not include 
Ryan, L. \& Maxwell, C. (2016) 'Social Class and Sociology: The State of the Debate Between 1967 and 1979', Sociology E-Special Issue 3, also in 50(1).

those leading thinkers from the period. But obviously, we are never going to please everyone. We are bound, inadvertently, to offend a few people by some seemingly careless omissions apologies in advance. We assure readers that we agonised long and hard over our choice as we whittled this down from an initial long list. However, we hope that readers will be intrigued and surprised by some of the perhaps unfamiliar authors we have included here. For example, we were both determined to include the paper by Elizabeth Garnsey whose work makes a convincing case for including women in class analyses, albeit path-breaking at the time, was completely unknown to us.

In making our final selection we sought to reflect some of the key themes around class that were apparent in the journal during this period. Embourgeoisement was clearly an interest among sociologists not just in Britain but also in other countries, as demonstrated by the many publications in Sociology during the late 1960s and into the 1970s. Changing class identities, practices and issues of social and geographical mobility featured across a wide range of articles by many different authors. The role of trade unions was also a recurring theme across many papers. Gender was also an emerging interest at the period. We have sought to reflect these interests in our selection though clearly this cannot be a representative sample. We were also struck by the methodological approaches of the period, in particular, the wide spread use of the social survey as a method of data collection. We will return to these themes in more detail in the sections below.

Among the four groups of e-special editors it was also agreed that, in addition to papers from our specific period, we would add some papers from other periods relevant to our particular theme, to indicate how concepts and/or methodological approaches had changed over time. Our selection of two recent papers may appear eclectic. Savage et al. (2013) is not only one of most downloaded papers ever in the journal's history, but it is also interesting in the context of this especial in demonstrating how class can be conceptualised and researched in the $21^{\text {st }}$ century. The paper by Vincent et al. (2012), using qualitative methods, is perhaps more typical of research published in the journal in recent decades, as discussed below. But we feel that this also exemplifies how class is now more usually approached through an intersectional lens. The focus on Black middle class parents shows how British society and indeed British sociology have changed and evolved over time, while key concerns such as inequality remain as salient as ever.

\section{Understanding social class}

The papers selected for this e-special issue tended to explore one of three broad, but interconnected issues relating to social class. First, some studies focused on social mobility and the extent of social stratification found within a society (Goldthorpe et al., 1967; Parsler, 1970 and Newman, 1979). Second, other papers examined the consequences of geographical mobility particularly among the middle classes - on social and kinship relations (Bell, 1968; Payne 1973). Third, research emerged during this time period which not only set out to explore whether increasing affluence had led to changes in social and cultural practices (the focus of work on embourgeoisement), but also to examine how people articulated understandings of social class (Hiller, 1975; Moorhouse, 1976), and the various ways differences in social class emerged in everyday practices, such as the use of language in child-rearing practices (Bernstein and Henderson, 1969).

Two seminal studies dominated British sociology in the 1960s (and beyond - according to Crompton and Scott, 2000) - Glass's Social Mobility in Britain survey undertaken in 1949, and 
Ryan, L. \& Maxwell, C. (2016) 'Social Class and Sociology: The State of the Debate Between 1967 and 1979', Sociology E-Special Issue 3, also in 50(1).

Goldthorpe et al.'s Affluent Worker Study of 1961-62. These studies categorised class through identifying occupational status and a worker's position in relation to the means of production. Glass was concerned with assessing rates of inter-generational social mobility between classes. Goldthorpe et al.'s survey, influenced by Weberian approaches to thinking about social class, sought to examine the consequences of such social mobility for the working classes. With the changing landscape of Western economies, particularly notable since the late 1940s, such as increasing affluence among many sections of society, the unfettered promotion of desires for consumerism, and the automation of manufacturing affecting industrial relations - the thesis of embourgeoisement argued that with such growing prosperity, the nature of the working classes was changing and many members of the labouring classes would become more bourgeois or middle-class. Goldthorpe, Lockwood, Bechhofer and Platt set out specifically to consider this thesis and examined whether the practices of those members of the working class experiencing higher levels of income and more acquisitiveness consumption practices were in fact changing the way class identities were being conceptualised, and the kinds of values and outlooks shaping everyday lifestyles.

Goldthorpe et al. (1967) argued that despite increased levels of income and ownership of consumption goods usually associated with being middle-class, the manual workers in their study (the definition of working-class being used here) still experienced significantly less mobility than their non-manual/middle class counterparts. This was assessed both in terms of levels of income earned, but also in the extent of changes in the nature of their work. For manual workers, their employment conditions still required them to engage in repetitive forms of work, with little possibility for promotion or taking on supervisory roles. Furthermore, the manual workers' patterns of sociability were not observed to have extended to include members of the middleclass, but were instead limited to immediate family and a few other working-class contacts. Finally, these workers did not, as espoused by the thesis of embourgeoisement, express a change in political outlooks to one that viewed the Conservative party as representing their needs. Ultimately, Goldthorpe et al. (1967) concluded: 'the position of a group within a system of social stratification is not decisively determined by the income or possessions of its members, but rather by their characteristic life-chances and experiences and by the nature of their relationships with other groups' (p. 27). Fundamental to this distinction is that these manual workers must sell their labour for an income.

Newman (1979) followed on from such a conclusion by offering his own challenge to the key assumptions underlying the embourgeoisement thesis. Newman reviewed previous arguments and studies which had supported the emergence of the idea of a 'newly acquisitive affluent worker'. He then put forward the suggestion that the theory of corporatism might offer an explanation for the emergence of this 'myth', arguing that acquisitive, non-politicised and privatised modes of economic and social relations had become the norm in Western societies, which inherently promoted this belief in a process of embourgeoisement.

Parsler (1970) also engaged with the thesis of embourgeoisement in his research, but focused on the Australian case. He argued that the egalitarian ideology of classlessness and compulsory arbitration within the employment sector found within Australian society might offer a context in which embourgeoisement may be more likely to take place. Parsler compared the earnings of 'blue-collar' workers, 'white collar' workers and the 'middle class, mainly professional group' ( $p$. 176). Such a differentiation offers a more complex way of thinking about social stratification - by differentiating the working-class into two groups. The key finding from this study was that despite 
Ryan, L. \& Maxwell, C. (2016) 'Social Class and Sociology: The State of the Debate Between 1967 and 1979', Sociology E-Special Issue 3, also in 50(1).

different levels of income between blue- and white-collar workers in Melbourne (a larger difference than found in similar studies in the UK and USA), the differences between the middle class(es) and these two groups of lower-income, non-professionalised workers were significantly greater. Drawing on a Weberian position, Parsler argued that for the working-class to aspire to income levels and professional positions held by the middle-classes, their children would be required to seek the necessary educational credentials in order to be able to compete for such futures.

Rosemary Crompton's 1976 article, meanwhile, focused specifically on the middle classes, seeking to make sense of how the expansion of this group was changing our conceptualisation of social class in Britain. In her paper she offers a critique of neo-Weberian analyses to date, and argued instead that a Marxist analysis of the class situation of white collar workers would give 'a better understanding of the propertyless middle class' (p.407). Crompton went on to argue that the growing middle class occupied a structurally ambiguous situation in British society. White collar workers exemplified this ambiguity as they were neither proletariat nor bourgeoisie. In addition, her paper also acknowledged the 'considerable variations' among white collar workers and acknowledged that it may be misleading to refer to the class situation of such a 'loosely defined' grouping (p. 420). The ambiguous nature of this grouping, she concluded, may be reflected in heterogeneous and 'even contradictory forms of collective representation' (p. 423) found among them.

Linked to Rosemary Crompton's contribution, is a broader, second strand of research show-cased in the papers selected for this e-special issue - focused specifically on the experiences of the middle classes. Bell (1968) examined relations within extended middle class families, where parts of a family had moved away. The findings from this study challenged the suggestion that in advanced industrialised societies kinship across generations is weakened and that individual family units operate fairly independently. In this particular article, Bell (1968) found that the fathers or fathers-in-law (to the head of the household who had moved away) were still supporting the new family unit financially, which augmented their standard of living, thus securing and advancing the new family's position.

Payne (1973), meanwhile, sought to consider more closely the implications of geographical mobility for middle class families - considering not only the fact of 'migration' but also of 'integration in local social milieux' (p. 423). Critically, Payne emphasised, just as Bell had earlier, that family relations shape and are shaped by mobility. Thus, whether a family has children and/or is a dual career household, and depending on the nature of their relationships with other friends and family, will influence the 'migrant's' orientation to the new geographical and social space they had moved into.

The third key theme running through these papers link to the articulations and practices of social class, as closely observed or elicited through discussions with particular groups. Hiller (1975), for instance, captured 'everyday conceptions of class' (p. 280) and concluded that despite financial means/the economic shaping of class narratives, participants offered quite sophisticated and differentiated descriptions of the various social groups around them. Meanwhile, Bernstein and Henderson (1969) offered an analysis of the ways working- and middle-class mothers used language differently in their child-rearing practices. Papers such as this and Hiller's begin to mirror more closely the approaches taken in more recent writings on social class, also published in 
Ryan, L. \& Maxwell, C. (2016) 'Social Class and Sociology: The State of the Debate Between 1967 and 1979', Sociology E-Special Issue 3, also in 50(1).

Sociology - see Payne and Grew (2005), Reay (2005), Nayak (2006), Rollock et al. (2011), Perrier (2013) to name but a few.

The studies examining class identifications and practices, and how social and geographical mobility shape these, were attempts to move beyond a conceptualisation of class as entirely tied to a society's occupational structure. Yet, despite the importance of engaging with the social / the relational - such a large focus of writing today on social class - writers such as Devine and Savage (2000), and Savage and Williams (2008) continue to emphasise the critical importance of considering how material inequalities and the increasing financialisation of society drives social inequality and processes of social closure, which prevent possibilities for social mobility and strongly shape social class relations and identifications.

This Savage et al. (2013) have attempted to do in a more recent, but highly engaged-with, paper published in Sociology. Savage and colleagues, like Glass and Goldthorpe et al., undertook a largescale survey ('The Great British Class Survey'), developing a class schema based on economic, social and cultural dimensions of class. Here, as in many more recently-published papers we see the significant influence of Bourdieu on writing about social class. Savage et al. (2013) considered levels of income and property ownership, types of employment/professional status, cultural lifestyles, and levels and types of sociability, when differentiating between seven kinds of social classes found today. Their data have also allowed them to consider social mobility, and how education and geography shape rates and outcomes of such mobility. Interesting, but largely critical responses to this important new work can be found in a series of the articles commissioned for volume $48(3)$ of Sociology.

The second, contemporary paper we have included in this e-special issue - by Vincent et al. (2012) - takes a more intersectional and qualitative approach to studying social class, and is perhaps more representative of the kinds of research being done in this field, in Britain today. Vincent and colleagues look closely at how race but also gender shape class identifications and practices, and continue to emphasise the importance of education in both negotiations of class and as a perceived strategy for securing future social class location (a point also made by Parsler in his 1970 paper).

While conceptualisations of class are a key point of interest across all the papers in this e-special, another salient point is how class can be researched. We consider these methodological approaches in the next section.

\section{Methodological Approaches to social class analysis and debate in the 1960s and 1970s}

Articles published in the journal during the 1960s-70s demonstrate the widespread use of the sample survey, even in small-scale, local studies. As a result, statistical analysis and tables of numerical data are common features in many of the articles reviewed and presented here. Over time, however, this research approach has gradually been eclipsed by two developments in particular.

Firstly, over the last thirty years or so, British sociology has undergone a marked shift towards qualitative methods (Payne et al., 1989 - cited in Williams et al., forthcoming). Hence, interviews and focus groups have largely replaced the sample survey method favoured by a previous generation of researchers. Savage and Burrows (2007) go so far as to suggest that British 
Ryan, L. \& Maxwell, C. (2016) 'Social Class and Sociology: The State of the Debate Between 1967 and 1979', Sociology E-Special Issue 3, also in 50(1).

sociology is comparatively unusual on the global scene in its embrace of the in-depth interview as the preferred research method. The massive expansion of sociology teaching across the university sector during the 1970s and 1980s, not only led to a broadening of research interests and topics but also coincided with a range of innovations in how to do research. Non-quantitative methods seemed to appeal more to those interested in studying issues around gender relations and identity politics. This resulted, as Cohen et al. (2011) argue, in quantitative approaches being regarded with suspicion by many undergraduates and lecturers, often labelled 'positivistic' and 'masculine', associated with the patriarchal dominance of traditional academia. However, Williams et al. (forthcoming) also suggest that the mundane issue of resources may partly explain the shift towards qualitative methods. Small scale, qualitative studies were simply cheaper to deliver and required far fewer resources than expensive survey work. For many cash strapped sociology departments during the 1970s-80s, Williams et al. suggest, the shift towards qualitative research may have been pragmatic as much as epistemological.

Secondly, in recent years, the rise of big data has led to the emergence of large scale statistical analyses supported by advanced computer software. In the present era every aspect of our daily lives generate data; from our use of social media to public transportation (McKie and Ryan, 2012). We are all continually bombarded by online consumer surveys assessing everything from our satisfaction with dental treatment to experiences of using a local gym. For the sociologist this may be a mixed blessing. While, large commercial data are generated, the proliferation of social surveys may be perceived as a nuisance and, as it is no longer an 'honour' to be asked our opinion (Savage and Burrows, 2007), resulting in falling response rates. The rise of big data has provoked concerns that British sociologists are unable to count (Williams, et al., 2008) and that sociology graduates lack the statistical and technical skills necessary to engage with and evaluate the burgeoning mass of large data sets (Williams et al., forthcoming). Despite considerable investment in developing quantitative skills (such as the Q-step programme, for example), there is evidence to suggest that many sociology undergraduates would rather write an essay than undertake statistical analysis (Williams et al., forthcoming).

Thus, looking back over Sociology in the 1960s-70s, the use of quantitative data may hold some insights and lessons for present day researchers and students. It is noteworthy, that far from being highly mathematical, most papers from that period present data in a very accessible and user-friendly way. For example, in her highly innovative and thought provoking paper, Elizabeth Garnsey uses census data to make a convincing argument for including women in analysis of class stratification. Anticipating the argument made by later feminist scholars such as Cohen et al. (2011), Garnsey uses official statistical data to challenge the myopia of established sociological research of the period. It should be noted, however, that like many other papers in Sociology during that period, statistics are usually used descriptively in tables containing percentages without presenting any further kinds of more complex analysis.

Although the sample survey method was hugely popular in the 1960s and 1970s, it should be noted that many of these surveys were administered face-to-face and take the form of highly structured interviews. In fact, in many cases they are described as 'interviews' though the numbers of 'respondents' involved would suggest something quite different from more recent interview techniques. It is not uncommon for researchers to refer to several 'hundreds of interviews'. A good example of this technique is illustrated by Goldthorpe et al. (1967) in what has been described as the most celebrated sociological study ever carried out in Britain (Savage and Burrows, 2007). Having carried out interviews with 229 manual workers (each interviewed 
Ryan, L. \& Maxwell, C. (2016) 'Social Class and Sociology: The State of the Debate Between 1967 and 1979', Sociology E-Special Issue 3, also in 50(1).

twice) and 54 lower level white collar workers (interviewed once), Goldthorpe and his colleagues present the data largely in numerical format, for example, describing the composition of friendship networks using percentages. Similarly, Moorhouse (1976) refers to 'interviews' carried out with 331 tenants in a Barking housing estate. These data are presented in table format again using percentages.

The quantification of interview data is even more apparent in the case of Hiller (1975) who carried out 150 interviews with Australian men but presents the findings using a series of seven very detailed tables of percentages. However, the fact that some categories in the table refer to only three or four people suggests that the data could have been presented in a more qualitative way. The irony here is that Hiller makes a case for using smaller scale studies in order to understand how social actors talk about, and make sense of, social stratification. But perhaps he thought his findings could carry more weight if they were presented in table format?

While many of the papers in this e-special issue of Sociology focus on working class participants, we have included a few papers that directly compare the working and middle classes.

Interestingly, two of these comparative studies relate to women.

Although his work has to some extent been eclipsed by the later work of Bourdieu, Basil Bernstein was a pioneer of research on class, education and what might now be called 'cultural capital'. Several of his papers featured in Sociology during the period of our investigation. We chose to include here his paper with Henderson, published in 1969, entitled 'Social class differences in the relevance of language to socialisation'. In this study three hypotheses are tested using a 'closed schedule instrument' with a sample of 100 mothers, derived from a larger sample of 120 respondents who live in a 'middle class area' and 192 who live in a 'working class area'. The results are presented in table format using mean scores and percentages.

In attempting to explain their findings, Bernstein and Henderson point to the differences in how knowledge is transmitted according to class: the relatively passive working class child as compared to the relatively active middle class child. Thus, the authors suggest, the working class and middle class have different concepts of learning. The socialisation of the middle class child emphasises autonomy. The authors draw upon their wider body of research, with a larger sample of mothers over several years, to reinforce their findings. These findings suggest that middle class mothers are less likely to avoid answering difficult questions put to them by their children. Middle class mothers are more likely to offer explanations to their children and less likely to use coercive methods of control. This refers back to Bernstein's earlier work on elaborated and restricted language codes. The wider implications of this study are explained in terms of the potential discontinuities experienced by the child when entering the school system. Working class children in particular may find that the form of socialisation and passive learning experienced in the home clashes with the active learning expected in the school environment, causing a sense of discontinuity. The authors conclude that their initial hypotheses have been confirmed by the data but acknowledge the need for more 'small scale, naturalistic and experimental studies' (Bernstein and Henderson, 1969, p. 17) to assess how mothers actually behave in practice.

For the modern reader, the stark contrast between middle class and working class mothers may feel somewhat uncomfortable. In reading these early issues of the journal, we were struck by the absence of reflexivity. There is little discussion of how, where or by whom data were collected. There is no reflection on how tenants engaged in a rent strike in Barking, for example, may have 
Ryan, L. \& Maxwell, C. (2016) 'Social Class and Sociology: The State of the Debate Between 1967 and 1979', Sociology E-Special Issue 3, also in 50(1).

reacted to university researchers coming into the area and asking them a series of rather personal questions. To the modern reader of Sociology, especially those schooled in feminist approaches to reflexivity (see Nowicka and Ryan, 2015), the lack of any discussion of positionality is particularly striking. Clearly, following the academic conventions of the time, the researchers are entirely absent from the study descriptions. There is no discussion of how the gender, age or, ironically enough, the class background of the researchers may have influenced the research field. In addition, there are no assurances given to journal readers that ethical procedures were duly observed throughout the research process. Obviously, it would be inappropriate to judge earlier generations of sociologists by the rigorous (and often highly bureaucratic) processes of ethics governance enforced today. Nonetheless, it is fascinating to observe not only how ways of doing, but also ways presenting and describing empirical research have changed over time.

The other comparative paper which focuses on women is 'Psychiatric disturbance among women' by Brown et al. (1975) and offers an interesting approach to the study of class stratification. In their highly cited paper 'The Coming Crisis of Empirical Sociology' Savage and Burrows (2007), questioned the extent to which sociological research can establish causality. The paper by Brown et al. (1975) ambitiously sought to go beyond association to establish causality. 'While there is unanimity about correlation between class and rates of psychiatric disturbance, nothing has been convincingly established about causality' (p.226). Using the popular method of a local neighbourhood study, the researchers compare two samples of women - a group of 114 patients with a diagnosis of depression and a random sample of 220 women. In addition to standardised psychometric tests, the researchers also used a range of interview questions to explore life events. The samples were then divided into middle class and working class groups. The results are presented in tables, using percentages, though $\mathrm{p}$-values are also presented to establish statistical significance. Findings show that women who are not employed seem more vulnerable to depression, but the authors acknowledge this may be as much to do with boredom and social isolation as with financial resources. Brown and colleagues conclude that structural factors such as poor housing may, in turn, lead to tensions between spouses and exacerbate the stress associated with having larger families. In this way the paper appears to consider mechanisms of causality, while acknowledging the highly complex nature of social life, thus anticipating the work of later scholars (see Abbott, 1998). The paper ends with a clear call to action: 'unequal distribution of such risk is the result of more widely recognised inequalities in our society... we believe that it constitutes a major social injustice' (p. 248).

\section{Conclusions}

While sociologists continue to be interested in class, social mobility, class practices and identities, the papers presented here clearly illustrate how ways of conceptualising and researching class have changed over time. By including a small number of more recent papers in this e-special issue, we have also sought to indicate the increasing awareness of the plurality of working and middle class groupings and different class fractions. While recent research clearly shows a greater acknowledgement of the effect of gender and race/ethnicity in shaping class practices and relations, it is apparent that some earlier researchers were also tackling some of these complex issues (see Garnsey, 1978 for instance).

With the contemporary, growing shift towards big data, there are obvious attractions for researchers who wish to undertake large quantitative studies. This volume of data allows us to make broader pronouncements about how social class groupings might be identified and to 
examine more closely the potential for social mobility at a particular moment in time and place, and the relationship between education, labour market structure and processes of mobility. The challenge for sociologists today - as in the past - is how to design studies that offer large scale data without losing sight of the personal narratives and insights derived through in-depth qualitative studies, that have been so crucial to understanding lived experiences of class.

The Sociology back catalogue offers valuable insights into changing sociological approaches over time. Clearly, from its inception, the journal has been at the cutting edge of social research. We hope this small serving of selected articles will whet readers' appetites and encourage researchers to do further digging to uncover more delights. The articles here remind us that older sociologists were aware of the nuances around class. This behoves us to think more about how our understanding of class today can continue to draw upon and learn from these classic papers and methods.

\section{Endnote:}

[1] To celebrate the 50th anniversary, the editorial board decided to produce four e-special issues reflecting the contributions of the journal across the decades. Each of the four e-specials focuses on a different theme ('1967-1979 Sociology and Social Class' edited by Ryan and Maxwell; 'Sociology in the 1980s - The Rise of Gender' edited by Roth and Dashper; 'Self-Identity and Its Discontents: Sociology in the 1990s' edited by Skinner, May and Rollock; '2000-2010 Sociology and its Boundaries' edited by Jawad, Dolan and Skillington).

\section{List of selected papers included in this special issue:}

1. Goldthorpe J H, Lockwood D, Bechhofer F and Platt J (1967) The Affluent Worker and the Thesis of Embourgeoisement: some preliminary research findings. Sociology, 1(1): 11-31.

2. Bell C (1968) Mobility and the Middle Class Extended Family. Sociology, 2(2): 173-184.

3. Bernstein, B and Henderson D. (1969) Social Class Differences in the Relevance of Language to Socialization. Sociology, 3(1): 1-20.

4. Parsler R (1970) Some Economic Aspects of Embourgeoisement in Australia. Sociology, 4(2): 165-179.

5. Payne G (1973) Typologies of Middle Class Mobility. Sociology, 7(3): 417-428.

6. Hiller P (1975) The Nature and Social Location of Everyday Conceptions of Class. Sociology, 9(1): 1-28.

7. Brown G W, Ni Bhrolchain M and Harris T (1975) Social Class and Psychiatric Disturbance among Women in an Urban Population. Sociology, 9(2): 225-254.

8. Crompton R (1976) Approaches to the Study of White-Collar Unionism. Sociology, 10(3): 407426.

9. Moorhouse H F (1976) Attitudes to Class and Class Relationships in Britain. Sociology, 10(3): 469-496.

10. Garnsey E (1978) Women's Work and Theories of Class Stratification. Sociology, 12(2): 223243.

11. Newman O (1979) The Newly Acquisitive Affluent Worker? Sociology, 13(1): 35-46.

12. Vincent C, Rollock N, Ball S J and Gillborn D (2012) Raising Middle-class Black Children: Parenting Priorities, Actions and Strategies. Sociology, 47(3): 427-442. 
13. Savage M, Devine F, Cunningham N, Taylor M, Li Y, Hjellbrekke J, Le Roux B, Friedman S and Miles A (2013) A New Model of Social Class? Findings from the BBC's Great British Class Survey Experiment. Sociology, 47(2): 219-250.

\section{$\underline{\text { References }}$}

Abbott A (1998) The Causal Devolution. Sociological Methods and Research 27: 148-181.

Cohen R L, Hughes C, and Lampard R (2011) The methodological impact of feminism: a troubling issue for sociology? Sociology 45: 570-86.

Crompton R. and Scott J. (2000) Introduction: the state of class analysis. In: Crompton R, Devine F, Savage M, et al. (eds) Renewing Class Analysis. Oxford: Blackwell Publishers, 1-15.

Devine F and Savage M (2000) Conclusion: renewing class analysis. In: Crompton R, Devine F, Savage M, et al. (eds) Renewing Class Analysis. Oxford: Blackwell Publishers, 184-99.

McKie L and Ryan L (2012) Exploring trends and challenges in sociological research. Sociology 40(5): 813-831.

Nayak A (2006) Displaced Masculinities: Chavs, Youth and Class in the Post-industrial City. London: Sage.

Nowicka M and Ryan L (2015) Beyond Insiders and Outsiders in migration research: Rejecting A priori commonalities. Introduction to the FQS Thematic Section on "Researcher, Migrant, Woman: Methodological Implications of Multiple Positionalities in Migration Studies" [34 paragraphs]. Forum Qualitative Sozialforschung / Forum: Qualitative Social Research, 16: Art. 18, http://nbn-resolving.de/urn:nbn:de:0114-fqs1502183.

Payne G and Grew C (2005) Unpacking 'class ambivalence': Some conceptual and methodological issues in accessing class cultures. Sociology 39: 893-910.

Perrier M (2013) Middle-class mothers' moralities and 'concerted cultivation': Class others, ambivalence and excess. Sociology 47: 655-70.

Reay D (2005) Beyond consciousness? The psychic landscape of social class. Sociology 39: 911-28.

Rollock N, Gillborn D, Vincent C and Ball S J (2011) The public identities of the black middle classes: Managing race in public spaces. Sociology 45: 1078-93.

Savage M and Burrows R (2007) The coming crisis of empirical sociology. Sociology 41: 885-99.

Savage M and Williams K (2008) Remembering Elites. Oxford: Blackwell Publishing.

Williams M, Hodgkinson L, Payne G and Poade D (2008) Does British sociology count? Sociology students' attitudes toward quantitative methods. Sociology 42: 1003-22.

Williams M, Payne G and Sloan L (forthcoming) Making Sociology count: Some evidence and context in the teaching of quantitative methods in the UK. In: McKie L and Ryan L (eds) An End to the Crisis of Empirical Sociology? Trends and Challenges in Social Research. London: Routledge.

Louise Ryan is Professor of Sociology and Co-Director of the Social Policy Research Centre at Middlesex University. She has a particular interest in research methods and recently guested 
edited (with Magdalena Nowicka) a special issue of Forum: Qualitative Social Research on the theme of positionality and reflexivity in migration research. Louise is also co-editor of a new book (with Linda McKie) entitled: An end to the crisis of empirical sociology? Trends and Challenges in social research (Routledge, 2016). Louise is currently working on a large European funded project on young people at risk of becoming early school leavers (with D'Angelo, Kaye and Lorinc).

Claire Maxwell is a reader in sociology of education at UCL Institute of Education, University College London. Her work focuses on elite and private education across national contexts. Her most recent study - Top Girls - examined the experiences of young women being privately educated in England, seeking to understand how privilege, agency and affect were mutually constituted. Claire is co-editor (with Peter Aggleton) of Elite Education. International Perspectives (Routledge, 2015) and has a paper in recent special issues on elite education, published in 2015, of the British Journal of Sociology of Education and International Journal of Qualitative Studies in Education. 